\title{
SOEP
}

SOEPpapers

on Multidisciplinary Panel Data Research

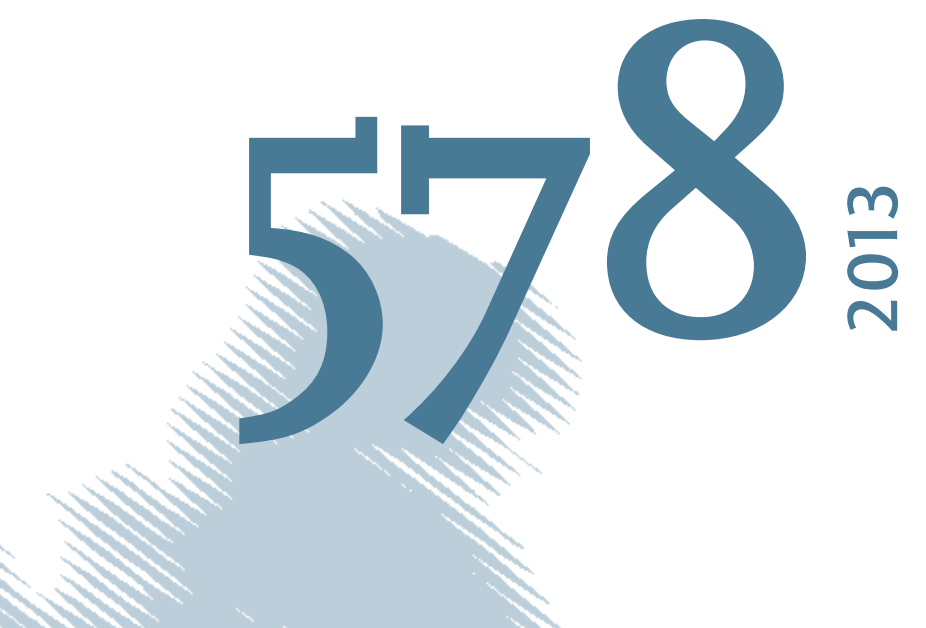

\section{Prosocial Attitudes in the Public and Private Sector: Exploring Behavioral Effects and Variation across Time}




\section{SOEPpapers on Multidisciplinary Panel Data Research}

at DIW Berlin

This series presents research findings based either directly on data from the German SocioEconomic Panel Study (SOEP) or using SOEP data as part of an internationally comparable data set (e.g. CNEF, ECHP, LIS, LWS, CHER/PACO). SOEP is a truly multidisciplinary household panel study covering a wide range of social and behavioral sciences: economics, sociology, psychology, survey methodology, econometrics and applied statistics, educational science, political science, public health, behavioral genetics, demography, geography, and sport science.

The decision to publish a submission in SOEPpapers is made by a board of editors chosen by the DIW Berlin to represent the wide range of disciplines covered by SOEP. There is no external referee process and papers are either accepted or rejected without revision. Papers appear in this series as works in progress and may also appear elsewhere. They often represent preliminary studies and are circulated to encourage discussion. Citation of such a paper should account for its provisional character. A revised version may be requested from the author directly.

Any opinions expressed in this series are those of the author(s) and not those of DIW Berlin. Research disseminated by DIW Berlin may include views on public policy issues, but the institute itself takes no institutional policy positions.

The SOEPpapers are available at

http://www.diw.de/soeppapers

\section{Editors:}

Jürgen Schupp (Sociology)

Gert G. Wagner (Social Sciences, Vice Dean DIW Graduate Center)

Conchita D'Ambrosio (Public Economics)

Denis Gerstorf (Psychology, DIW Research Director)

Elke Holst (Gender Studies, DIW Research Director)

Frauke Kreuter (Survey Methodology, DIW Research Professor)

Martin Kroh (Political Science and Survey Methodology)

Frieder R. Lang (Psychology, DIW Research Professor)

Henning Lohmann (Sociology, DIW Research Professor)

Jörg-Peter Schräpler (Survey Methodology, DIW Research Professor)

Thomas Siedler (Empirical Economics)

C. Katharina Spieß (Empirical Economics and Educational Science)

ISSN: 1864-6689 (online)

German Socio-Economic Panel Study (SOEP)

DIW Berlin

Mohrenstrasse 58

10117 Berlin, Germany

Contact: Uta Rahmann | soeppapers@diw.de 


\title{
Prosocial Attitudes in the Public and Private Sector: Exploring Behavioral Effects and Variation across Time
}

\author{
Alexander Kroll ${ }^{*}$ \\ Dominik Vogel $^{* *}$ \\ * Assistant Professor of Public Administration \\ School of International and Public Affairs \\ Florida International University \\ Miami, USA \\ ** Ph.D. Candidate \\ Department of Public and Nonprofit Management \\ University of Potsdam \\ Potsdam, Germany
}

\begin{abstract}
This paper will contribute to a growing body of research on the concept of public service motivation and its effects. It addresses two important though still largely unexplored questions: How stable or dynamic are prosocial attitudes, and do differences among employees or the individual changes in their attitudes over time matter, in order to explain the performance of prosocial behavior? To learn more about public employees in this respect, the paper will compare them with their counterparts in the private sector and explore multiple waves of data from the German Socio-Economic Panel Study that covers a time period of sixteen years. We find that prosocial attitudes are mostly stable, there are no socialization effects in either sector, and differences among employees matter a great deal. We also detect longitudinal effects, suggesting that increases in prosocial motivation trigger related behaviors, however, at the risk of neglecting others.
\end{abstract}




\section{Introduction}

Prosocial motivation is a concept that has become of major importance in public administration research (Perry and Wise 1990; Perry, Hondeghem, and Wise 2010). Employees who were found to be driven by altruism and other-orientation were also more likely to work in the public sector (Lewis and Frank 2002; Steijn 2008; Vandenabeele 2008; Wright and Christensen 2010), less dependent on utilitarian incentives (Rainey 1982; Bright 2009), and they performed better on the job if compared with other employees in the public service (Vandenabeele 2009; Bellé 2013). Though there is a growing literature that aims at further qualifying these observations (Bright 2008; Christensen and Wright 2011; Moynihan and Pandey 2008; Steijn 2008; Wright and Pandey 2008), one of the "unanswered questions about public service motivation” (Wright and Grant 2010) is whether the concept is a dynamic state or stable trait. Such a distinction has critical implications, because in the first case a prosocial motivation could be conceptualized as a personal disposition that varies over time and can be changed, whereas in the latter case it would be something static that only differs among people.

This paper will address this topic comparing public- and private-sector employees. We believe that we can learn a lot about public employees if we do not only study their attitudes and behaviors but actually have a reference group to compare them with. The first part of the paper will be devoted to explore the variation of prosocial attitudes across time as a function of socialization. Starting from the hypotheses that employees in the public sector are likely to have stronger prosocial values than employees in the private sector due to attraction-selection effects, we will then continue to theorize about how these values might evolve over time. The two-sector design is particularly helpful here, because if socialization matters, we will expect different trends in both sectors. Our analysis will reveal how stable or dynamic a prosocial motivation is over a longer period of time. Though we will be able to tease out the broader 
effect of sector socialization, we do not test the impact of different management interventions which could also cause variation in prosocial motivation.

The second part of the paper will take our analysis one step further and examine the behavioral effects of prosocial motivation. Consistent with our focus in the first part, the lead question is whether differences in prosocial behavior are due to differences in attitudes among employees or caused by individual changes in their attitudes over time. The two-sector design will be used again to determine how generic these effects are. The behaviors under investigation are volunteering after hours and persistence at work, which can both be regarded as "prosocial”, when employees provide public services. Since performing both behaviors at the same time might create a trade-off for public employees, our design will make it possible to learn more about the nature of the effect of prosocial motivation which could be complementary or substitutional.

We believe that a better understanding of the conceptual nature of prosocial motivation and its effects will not only improve our theories but also yield relevant practical implications. For example, if the socialization in public-sector organizations is not sufficient to significantly increase employees’ prosocial values, managers have to think of interventions which could make a difference instead. Managers may even need to recruit prosocially driven people in order to foster a social norm that embraces related behaviors. Furthermore, if prosocial motivation is absorbed by one activity at the expense of another ("substitution”), then it needs to be treated as a scarce resource, and managers have to deliberately decide for what purposes they want to "make use" of it. If there is even a trade-off between realizing prosocial motivation at work or through volunteering, public organizations might lose critical motivational capital if their managers are not able to link employees' values to the mission of their organizations. 


\section{Prosocial Attitudes, Work Effort, and Volunteering}

In this theory section we will draw on the literature on prosocial motivation and public service motivation (PSM). Both types of motivation appear to be quite similar as they share a focus on other-orientation, altruism, self-sacrifice, and empathy (Perry, Hondeghem, and Wise 2010; Batson 1987; Kim et al. 2012; De Dreu 2006). Though both concepts clearly address a type of motivation that could be characterized as an antipode of self-interest, they are not identical. PSM differs from the broader term of prosocial motivation in the sense that it is particularly “animated by specific dispositions and values arising from public institutions and missions” (Perry, Hondeghem, and Wise 2010, 682). Moreover, prosocial motivation can be conceptually and empirically distinguished from intrinsic motivation, which emphasizes the importance of interest and enjoyment as drivers of effort (Grant 2008). The boundary between intrinsic motivation and PSM, however, does not seem to be very distinct. For example, one reason why people might score high on the PSM dimension "attraction to policy-making” could be that they are interested in politics or enjoy shaping political outcomes which would also be consistent with the presence of intrinsic motivation.

Though there are nuances in which PSM and a broader prosocial motivation differ, this paper's theory will be mainly built on the commonalities of both concepts and make use of their convergences. In the subsequent sections - and particularly when getting closer to the formulation of our hypotheses - we will confine ourselves to the use of the terms "attitudes" and “values” instead of “motivation” or "PSM". This is, as will be explained below, due to the fact that we can only use two single-item measures of employees’ prosocial orientation for our empirical test; and these measures seem to portray singular attitudes or values rather than comprehensive motivational constructs. 


\section{Prosocial Attitudes across Sectors}

When theorizing about prosocial motivation, we need to keep in mind that the existence of differences between sectors was one of the first hypotheses developed in this field. In fact, Perry and Wise (1990) wanted to explain why employees decided to join public organizations and thus came up with the concept of PSM - a prosocial motivation that employees can realize best when working in the public sector. Since then (and even before Perry and Wise’s seminal work, see Rainey 1982) several studies have tested this hypothesis and most of them found corroborating evidence (see, for example, pioneering studies by Wittmer 1991; Gabris and Simo 1995).

Though most research referred to the work by Perry and Wise (1990) and later Perry (1996), a good deal of them used heterogeneous measures of prosocial motivation and PSM. Houston (2000) and Steijn (2008), for example, used data from the General Social Survey and found that employees who highly valued the "meaningfulness of their work" were more likely to join the public sector. There is more support for the hypothesis that the public sector attracts employees with strong prosocial values. Lewis and Frank (2002) showed that people for whom it is important to be "useful to society" and to "help others" are more likely to want to work for the government. In accordance with this, Tschirhart et al. (2008) found that MBA and MPA students, who value to have "a career that allows them to help others”, also have a preference to work in the public or nonprofit sector.

However, there are also research results that are somewhat divergent. Andersen, Pallesen, and Pedersen (2011) examined physiotherapists in Denmark, a profession that can be found in the public and private sector. In contrast with other studies, they found no general differences in prosocial motivation among employees in both sectors. This is in line with what Christensen and Wright (2011) have suggested. It might not be the sector that makes the difference but the actual job attributes. They argue that there are jobs in the public as well as 
in the private sector which provide more and less opportunities for prosocially driven employees to realize their motivation. In another study, which was based on a sample of U.S. lawyers, they found that employees with a great other-orientation might not necessarily join public organizations at the beginning of their careers but are more likely enter this sector later on (Christensen and Wright 2011). Though these studies proposed enhancements of the original attraction-selection hypothesis, they do not invalidate its general argument, which is why it seems safe to begin building our theory on the following hypothesis.

Hypothesis 1: Employees working in the public sector have stronger prosocial attitudes than employees in the private sector.

In addition to the question of whether the public sector attracts employees who share high levels of prosocial motivation, it also seems to be highly relevant how such a motivation evolves over time, and whether a different socialization could cause different trends in both sectors.

Evidence in favor of the dynamic state of prosocial values comes from Kjeldsen and Jacobsen (forthcoming). Using the sample of Danish physiotherapists, mentioned above, they found that after working for about two years, the respondents’ PSM values had significantly changed. More support for the argument that prosocial values can vary across time can be found in an early study by Mortimer and Lorence (1979). They used two waves of panel data which covered a time span of ten years to study college seniors. They found comprehensive evidence that occupational values determine the selection of certain jobs which, in turn, enforce these values. In the case of other-oriented students who joined organizations with a social focus, however, this effect - though existent - did not achieve statistical significance.

Other research from the field of election studies suggests that personal predispositions, which are to a good extent comparable with prosocial values, tend to be rather stable across 
time. Judd and Milburn (1980) examined social attitudes towards racial integration, helping minorities, or the government's role in society and found that these did not essentially vary over time. Two more studies reported similar results using panel data which covered time periods of 18 respectively 23 years, concluding that adults' political predispositions remained largely constant (Jennings and Markus 1984; Sears and Funk 1999).

There is evidence in favor of both hypotheses. Some studies reported that prosocial values and predispositions are dynamic whereas others found support that they are widely stable. What we have not addressed thus far is, assuming that there is variation, whether we can expect different developments in the public and private sector due to a difference in socialization that employees might experience. Kjeldsen and Jacobsen (forthcoming) found that in the two years after finishing their training and starting to work, the studied cohort's PSM levels dropped down in both sectors, however, this decrease was less severe for public employees. Though the researchers categorized this observation as a "reality shock" rather than a function of long-term socialization, the buffering effect for public employees seems to indicate greater value congruence between prosocially driven people and public sector work. When taking a long-term perspective and considering the conceptual work by Perry and Wise (1990) and Perry, Hondeghem, and Wise (2010), we could even hypothesize that working in the public sector can enforce employees' prosocial values. If the public sector attracts people with strong prosocial attitudes, and these people spend most of their career serving the public, then it seems reasonable to assume that this again strengthens their original attitudes. If this reasoning holds true, the same socialization effect shall not occur when people join private sector firms.

Hypothesis 2 a : Across time, prosocial attitudes are dynamic, which is why they will increase with a steeper slope in the public sector than in the private sector. 
Hypothesis $2_{b}$ : Across time, prosocial attitudes are stable, which is why we will not find much variation in either sector.

\section{Complementary and Substitutional Effects of Prosocial Attitudes}

This section theorizes about the nature of the relationship of prosocial motivation and related behaviors. Whether potential effects of attitudes on behavior are triggered by differences among employees or differences across time is an empirical question that we will explore in our analysis. The function of this section is, however, to elaborate on the nature of this relationship which can be complementary or substitutional. Substitution means that employees can only engage in some prosocial activities at the expense of others ("absorption

effect”). Complementarity, however, exists when prosocial motivation is capable of triggering several prosocial behaviors simultaneously.

Prior research has shown that there is a positive relationship between public employees’ prosocial motivation and their work effort. On the one hand, they were found to be better at doing their assigned work compared with their colleagues (Naff and Crum 1999; Vandenabeele 2009), or their prosocial motivation moderated the performance effects of other person-related factors (Grant and Wrzesniewski 2010; Grant 2008). On the other hand, these employees were also found to show higher levels of extra-role behavior which goes beyond normal job expectations and is usually not recognized by formal reward systems (Leisink and Steijn 2009; Wright 2007). For example, some studies documented that prosocially driven employees are more likely to engage in organizational citizenship behavior, such as helping out their colleagues (Kim 2006; Pandey, Wright, and Moynihan 2008). Other studies reported that these employees tend to take on extra responsibilities and engage in performance management practices which can create additional effort but might also be useful to improve 
outcomes for the clientele they serve (Kroll and Vogel, forthcoming; Moynihan, Pandey, and Wright 2012). The explanation behind these observations is straightforward. Employees with strong prosocial values put extra effort in their work in the public sector, because these jobs make it possible to do good for others and thus transform their motivation into action.

Another way of realizing prosocial motivation is not through public sector work but volunteering after hours. There is one stream of literature which has examined the role of PSM for volunteering behavior. For example, Perry et al. (2008) found that both concepts are positively related; though this relationship can be mediated by other factors (see also Ertas 2012 and Lee 2011). Further evidence of the PSM effect on the performance of charitable activities comes from Clerkin, Paynter, and Taylor (2009) who studied a sample of undergraduate students and Coursey et al. (2011) who surveyed volunteer award winners.

Putting these findings together, we could assume that prosocial values can foster different prosocial activities. That is, prosocially driven public employees will on the one hand be persistent at work and put in extra hours to be able to help others and serve their clientele. On the other hand, they will also engage in volunteering after hours. Thus, we can hypothesize that a prosocial attitude might be conceptualized as a generic value which generally guides people's actions in various situations in life and which is capable of triggering several prosocial behaviors simultaneously.

Hypothesis $3_{\mathrm{a}}$ : Public sector employees with strong prosocial attitudes will show persistent work behavior and engage in volunteering after hours (complementarity effect).

However, the evidence presented above also allows an alternative reading. Though prior research found many different examples of in-role and extra-role behaviors as well as volunteering that was triggered by employees' prosocial values, it is difficult to find studies 
that have examined the involvement in one prosocial behavior while controlling for the involvement in another. In other words, though we can be quite sure that a prosocial attitude fosters certain behaviors, it is still possible that employees engage in one activity at the expense of another. For example, public employees who believe that they cannot realize their prosocial motivation through their job, let's say due to a lack of value congruence with the organization they work for (Moynihan and Pandey 2008), might use volunteering as an alternative outlet.

Substitutional effects would be also in line with Simon’s (1959) assumption of bounded rationality. Since time, capacity, and motivation are not endless resources, we could hypothesize that different prosocial activities will end up in a competition with each other and create trade-offs. Thus, being persistent at work in a public sector job might already "absorb” an employee's prosocial motivation which would make it impossible to engage in volunteering activities with the same intensity.

Hypothesis $3_{\mathrm{b}}$ : Public sector employees with strong prosocial attitudes will show persistent work behavior but not engage in volunteering after hours or vice versa (substitution effect).

\section{Control Variables}

We will also include control variables in our models to test their validity and gain additional insights about the nature of prosocial motivation. One factor is employees' political interest, which we expect will have a positive effect on job persistence (for public employees, Vandenabeele 2009) and volunteering (Bekkers 2005). We also included three job related variables. The first one is job satisfaction, which might have a positive effect on persistence at work (Judge et al. 2001; Vandenabeele 2009; Judge et al. 2001). The second variable is 
organizational tenure, which has been found to have a negative effect on persistence, at least for the public sector (Moynihan and Pandey 2007). A third variable is job prestige which is supposed to pick up on employees’ publicly recognized status and to a certain extent their hierarchical position. Additionally, we included four socio-demographic measures. One is the respondents' income, which we expect to be positively associated with the employees 'overtime and, based on Hackl, Halla, and Pruckner (2007), also with volunteering intensity. We chose age as a second socio-demographic control because it is generally accepted in nonprofit research that older people engage in volunteering activities more frequently (Tschirhart 1998; Bussell and Forbes 2002). In our cross-sectional model, we furthermore accounted for the two time-invariant factors "gender" and "years of education".

\section{Data and Methods}

\section{Data Source}

To test our theory, we will use data from the German Socio-Economic Panel Study (SOEP). ${ }^{1}$ The SOEP has surveyed a representative sample of 20,000 people in Germany every year since 1984, and it has generated panel data that are comparable to similar studies like the Panel Study of Income Dynamics (PSID) in the U.S. as well as the British Household Panel Survey (BHPS). Using this type of panel data has several advantages but also at least one disadvantage.

One major advantage is that these surveys provide data on the development of attitudes and behaviors of the sampled population across time, which has become the basis for

\footnotetext{
${ }^{1}$ The data of the German Socio-Economic Panel Study (SOEP) are collected and provided by the German Institute for Economic Research (DIW Berlin). We used version 26 (Socio-Economic Panel (SOEP) 2010). For further details on the SOEP see Wagner, Frick, and Schupp 2007
} 
a number of informative studies in the field of public administration that went beyond crosssectional analyses (Wright and Christensen 2010; Georgellis, Iossa, and Tabvuma 2011; Kelman and Friedman 2009). We will use the SOEP data to explore whether prosocial attitudes vary over time and whether we can observe different trends in the public and the private sector. We will also make use of the data's panel structure to sort out whether the effects of prosocial values on behavior will show up cross-sectionally and/or longitudinally. To put in another way, we want to find out whether it is the differences in attitudes among employees that matter or individual changes in the attitudes over a longer time period. Another advantage that comes with the SOEP data is that they provide information about each surveyed individual's job persistence as well as volunteering engagement, which makes it possible to study the effects on one behavior under the control of the effort being put in the other.

One disadvantage of working with the SOEP data is that most social science concepts were only measured by single items. Though this is a limitation of this paper, it seems to be the price we have to pay when we want to make use of a representative, balanced survey panel that provides information for more than two decades. Several recent publications based on similar data sets, which we have cited above, have shown that accepting this shortcoming is worth the important research it might generate.

\section{Sample and Measures}

For our analysis we could not use the whole SOEP data set, because our variables of interest have not been measured every year. The questions reflecting on prosocial attitudes were asked in 1992, 1995, 2004, and 2008. Out of these waves only three included measures for volunteering behavior $(1992,1995,2008)$, which is why our regression models were 
restricted to the data from these three waves. However, for the descriptive analysis of the prosocial attitudes we were able to make use of all four waves.

To be able to compare the public and private sector and in order to create a sufficient basis for the statistical analysis, we restricted the sample to those who consistently worked in one of the two sectors at all the points of time under study. This excluded all employees who have switched sectors or were at some point unemployed. We also aimed at creating a balanced panel by excluding those with missing values on the dependent variables or the two prosocial attitudes. As a result, we generated two data sets; one consists of three data waves and 1,569 respondents (including 375 public employees), and the other consists of four waves and 1,413 respondents (including 345 public employees).

All our measures can be found in the appendix. We use two different dependent variables in this paper, one if which is "volunteering". The SOEP participants were asked how often they engage in volunteering activities in clubs, associations, or social services, and possible answers were “at least once a week” (4), “every month” (3), “less than once a month” (2), "never” (1). We are aware that this is a categorical rather than a continuous measure, and we will explain below how we dealt with this in our analyses. The second dependent variable - persistence at work - is measured by self-reported hours of overtime per week.

In order to explain the variance in our dependent variables, we used two different prosocial attitudes. The first one is “the importance of social and political involvement”. The respondents were asked how important it is for them to be socially and politically involved which picks up on the same attitude as the PSM dimension "commitment to the public interest. In his measurement scale, Perry (1996) used similar items like "It is hard for me to get intensely interested in what is going on in my community" which is an example of a reversed measure. Another comparable item can be found in the revised PSM measure 
developed by Kim et al. (2012): "It is important for me to contribute to the common good". All these items indicate how strongly one values the commitment to social and public activities. The second prosocial measure can also be attributed to the research on PSM. To assess people’s “care for others”, the respondents were directly asked how important it is for them to "be there for others". This is related to the compassion dimension of the PSM concept which aims to capture the importance of social relationships and the compassion for others.

Most of our control variables are direct measures, which we find straightforward and reliable. This includes organizational tenure (years working for the same organization), income (in Euro), age (in years), years of education, and gender (Dummy; 1 = women). Job Prestige was measured using SOEP's magnitude prestige scale developed by Wegener (1992), which is a rating tool similar to the Standard International Occupational Prestige Scale (SIOPS). Two individually perceptual measures were used to capture political interest and job satisfaction. Participants have been asked how much they are generally interested in politics (1 = not at all; 4 = very much) and how satisfied they are with their job ( 0 = totally unhappy; $10=$ totally happy). Table 1 displays all descriptive information. To account for the panel structure of our data, the correlations (Pearson's r) were calculated for each wave separately and then averaged. The results from the table reveal that all variables are only moderately correlated and thus suggest discriminant validity. None of them exceeds a correlation of 0.5 , except for "years of education” and “job prestige”. We still did not drop either variable from our cross-sectional analysis, as they differ to the extent that one is time-invariant and the other is not.

[Table 1 about here] 


\section{Statistical Estimations}

In addition to the descriptive examination of how prosocial attitudes evolve over time and across sectors, this paper will investigate the causal effects of these attitudes on the two behaviors “persistence” and "volunteering”. To explore these effects, we will use a longitudinal and a cross-sectional perspective.

From a longitudinal perspective we want to study whether changes in an employee's prosocial values over time will also lead to changes in their work and volunteering behaviors. To identify these relationships, we will make use of fixed effects panel regressions, which eliminate all heterogeneity among individuals from the model, and thus partial-out time effects “within” individuals (Allison 2005; Wooldridge 2010). Focusing on effects across time also means excluding all time-invariant variables from our models, as these are by definition not able to account for the variation of the dependent variable. We decided to use fixed effects instead of random effects estimations, because we find the interpretation of the former's coefficients for a longitudinal analysis more straightforward (random effects models do not fully isolate intra-individual variation, Halaby 2004), and the Hausman Test $(\mathrm{p}<0.05)$ suggested that all but fixed effects estimators would be systematically distorted.

We will also use a more conventional cross-sectional perspective to study the effects of differences among individuals. In other words, we want to know whether employees with stronger prosocial values show different work and volunteering behaviors than those who reported lower levels of motivation. To examine these relationships cross-sectionally, we used Ordinary Least Squares (OLS) regressions. To account for the fact not all observations in our panel data set are independent (in fact, all observations that stem from the same person are supposed to be highly correlated), we clustered standard errors at the person level (Cameron and Trivedi 2005). We have not used random effects estimations because they are known to yield the same results as OLS if, like in our case, the panel is balanced. We also chose OLS 
for the sake of simplicity. Though one could argue that the use of ordered logits would be more appropriate for the "volunteering” regression (since volunteering was measured on an ordinal scale), we decided to use OLS because the results produced by both methods did not significantly differ, and this way the coefficients are better comparable to those of the “persistence” regression. We accounted for wave-specific effects in our longitudinal analysis, but since none of them was significant, and all other coefficients did not change significantly either, we did not ultimately include the year dummies in table 4.

\section{Results and Discussion}

\section{Descriptive Analysis}

Figure 1 shows the descriptive results for employees' levels of prosocial motivation across sectors and time. The top part of the figure displays the results for the item "importance of social and political involvement", while the bottom part focuses on the item "care for others”. Turning to our hypotheses, we find support that public sector employees have stronger prosocial attitudes than their colleagues from the private sector which confirms hypothesis 1 . The former scored on average higher on both attitudes than the latter, though the graphically displayed confidence intervals reveal that these differences are only significant for three out of four points in time if we consider the top part of figure 1 but not significant when looking at its bottom part.

[Figure 1 about here] 
Overall, this is corroborating evidence in favor of hypothesis 1 and prior research (Houston 2000; Lewis and Frank 2002; Rainey 1982; Tschirhart et al. 2008). However, the findings that the sector differences are only significant for one of the two items and that the average agreement with both items also seems to differ a great deal are unexpected and need to be explained. One plausible explanation is that both measures pick up on different aspects of prosocial motivation. Being in agreement with the statement that "social and political involvement is important” indicates the willingness to become active and do something. This seems to be more demanding than just stating broadly that "caring for others" is essential. This could be a reason why more people agreed with the latter item and why it thus discriminates less well between sectors.

Examining time trends, we find support for hypothesis $2 \mathrm{~b}$ rather than 2a. Both prosocial attitudes under investigation have been stable rather than dynamic in both sectors. In addition to "eye-balling”, which suggests that there are no clear trends, a look into the descriptive statistics lends support to this impression. Table 2 provides an overview of both items' stability and displays the points the respondents moved up or down on the used Likert scales over a period of sixteen years. ${ }^{2}$ A vast majority of all employees (see part B, social involvement: $58 \%$, care for others: $66 \%^{3}$ ) provided the same response across the sixteen years or changed their response only once by one Likert point but then remained in this position for the rest of the time. Less than $30 \%$ of the respondents from both sectors have altered their response to each item by two Likert points across all waves. This includes people who, for example, moved up the scale by one point in one wave and then down again in another; a pattern which would be proof for the stability of the attitudes rather than for a time trend. Though the table indicates that there are no major differences between sectors, part A

\footnotetext{
${ }^{2}$ We borrowed this method of analysis from Rice and Hilton 1996.

${ }^{3}$ We obtained these percentages from averaging the values from both sectors in part B.
} 
suggests that on average prosocial attitudes are a little more stable in the public sector. Part C provides further evidence that these values have been largely consistent between two waves at a time, which also holds for the longest time span between 1995 and 2004.

[Table 2 about here]

Our sample only includes employees who have not switched sectors in a period of sixteen years (some of them switched, however, from one organization to another within the same sector). In order to check whether this sample is exceptional or representative for employees more broadly, we compared their motivation scores with those of the "sector switchers”. The latter category constitutes a sample of three groups of employees $(n=53,77$, 78) who switched from the private to the public sector between two waves at a time. ${ }^{4}$ We find that these employees’ prosocial attitudes are as stable as those of our original sample (figures not reported here). After joining the public sector, the switchers' prosocial values do not significantly shoot up but look a lot like the lines we drew in figure 1 . In fact, with regard to the item “social involvement”, we find that the switchers' motivation scores end up exactly between the public- and the private-sector lines, suggesting that these employees might constitute their own static hybrid type in-between the two sectors.

From these findings we can infer that prosocial values are stable rather than dynamic and that there are no evident socialization effects in either sector. Though prosocially driven people are more likely to work in the public sector, just having such a job over almost two

\footnotetext{
${ }^{4}$ We did not include employees switching from the public to the private sector because we had difficulties distinguishing these people from those who did not actually switch sectors but kept working for governmentowned organizations which were legally privatized as a part of numerous corporatization initiatives in the 1990s.
} 
decades does not seem to be enough to increase this other-orientation. These results are also in line with previous research which has shown that comparable personal attitudes towards integration, minorities or the role of government are basic predispositions that, once developed, only marginally change in an adult's life (Judd and Milburn 1980; Sears and Funk 1999).

\section{Behavioral Effects}

Table 3 and 4 provide the results for the effect of prosocial attitudes on related behaviors. We find general support for the claim that such a relationship exists which overall holds in the cross-sectional and longitudinal models (eight out of twelve coefficients show a positive effect). Interestingly, the effect of prosocial motivation does not only occur for public-sector employees but seems to be a sector spanning concept, which is in agreement with what Kjeldsen and Jacobsen (forthcoming) and Christensen and Wright (2011) have found. Since it is more difficult for employees in the private sector to realize this motivation through their work, they engage in volunteering activities as an alternative outlet (see model 1 in table 3 and 4). To test hypotheses 3a and 3b, we will focus on the subsample of public employees and investigate potential complementary and substitutional effects. In each table there are four relevant coefficients, two of which describe the effects of prosocial attitudes on volunteering (model 2 in each table) and the other two the effects on persistence (model 4 in each table).

Cross-sectionally, we find more support for a complementarity effect and thus hypothesis 3a (see table 3). Public employees who have strong prosocial values are more likely to also be persistent at their job (see model 4) and at the same time still engage in volunteering after hours (one out of two coefficients is significant in model 2). This is in line 
with prior research that has documented the positive effects of prosocial motivation on several behaviors but has not controlled for potential trade-offs (Clerkin, Paynter, and Taylor 2009; Pandey, Wright, and Moynihan 2008; Wright 2007; Coursey et al. 2011). This result suggests that variation among employees matters a great deal. A prosocial motivation seems to guide people's behaviors in different life situations and therefore appears to be a concept broad enough to discriminate between different types of people.

Longitudinally, we find more support for a substitutional effect and thus hypothesis 3b (see table 4). When public employees' attitude towards social involvement becomes stronger over time, they increase their engagement with volunteering. At the same time, however, they do not put more effort into their work. Looking at the second attitude measure, we find clear support for a substitution effect. When public employees’ concern for others increases over time, they become more persistent at work but at the same time less likely to volunteer. These findings deviate from the cross-sectional ones, but they are not contradictory. Assuming that there are different broader types of prosocially driven employees, increases in their motivation will only be able to trigger additional job persistence if another behavior, such as volunteering, is reduced in return.

[Table 3 and 4 about here]

\section{Further Effects on Persistence and Volunteering}

In this section, we will take a brief look at the results of our control variables. Political interest has significant longitudinal effects which are also in line with the logic behind our 
idea of a behavioral trade-off discussed above. If private-sector employees' political interest increases over time, they reduce persistence at work but intensify engagement in volunteering. Another finding is that if those employees' job prestige increases, they will put more effort into their work (see table 4). When comparing differences among employees, we find another interesting effect for the subsample of private-sector employees. People are more satisfied with their jobs when they have to do less overtime but simultaneously can engage more in for volunteering activities (see table 3).

Cross-sectionally, we see that employees with higher incomes do more overtime (in both sectors) but this effect vanishes for public employees when using a longitudinal perspective. We also find that as public- and private-sector employees get older, they engage more in volunteering. These examples show that variations in effects are contingent on whether we compare employees with each other or track differences of individuals across time. We can also see that there are significant differences between the two sectors, for example, regarding the variables job satisfaction, organizational tenure, job prestige, or age. These findings should be considered when planning future research endeavors, specifying statistical models, and conducting additional sector comparisons.

\section{Limitations}

There are limitations to acknowledge, which need to be kept in mind, when generalizing from our results. We have reported that employees’ prosocial values are relatively stable across a time period of sixteen years. Though to a certain extent this does indicate that it might be quite a challenge for managers to trigger increases in their employees’ motivation, we would not ultimately conclude that PSM or comparable motivational concepts should only be treated as exogenous variables. 
We have not tested whether specific interventions (for example, variations in leadership, autonomy, or tasks) can increase prosocial attitudes, and a number of crosssectional studies have suggested that we find higher levels of PSM when employees have been led transformationally, when they hold leadership positions or have experienced HR management tools, such as job enrichment or professional development (Wright, Moynihan, and Pandey 2012; Bright 2005; Giauque, Anderfuhren-Biget, and Varone 2013). Another panel study reported that PSM increases when people get older, and it decreases with every year that an employee works for the same public organization (Vogel 2012). Furthermore, our own longitudinal analysis revealed that variations in prosocial attitudes, even when marginal, can trigger significant effects on people’s behavior.

A second limitation comes with the fact that we tried to study changes in attitudes using a four-point measurement scale. Though we agree that such a scale might not be sensitive enough to detect marginal variations in attitudes, another panel study by Kjeldsen and Jacobsen (forthcoming) has proven that it is possible to capture time-related changes in PSM using a similarly limited five-point measurement instrument. Considering these points, one main challenge for future research will be to examine the effects of management interventions on employees’ prosocial values using longitudinal designs.

\section{Conclusion}

This paper used panel data that covered a period of sixteen years to examine employees' prosocial attitudes in the public and private sector, potential time trends, and their effects on work effort and volunteering. We found that public employees have stronger prosocial values than their counterparts in the private sector, though this observation was not as clear-cut as expected. The paper also revealed that prosocial attitudes are largely stable 
across time in both sectors, which is evidence against socialization effects. Finally, we explored that public employees who are prosocially driven will also show more persistence at work and at the same time more volunteering after hours. However, if an employee's prosocial motivation increases over time, the trade-off between extra effort being put in their work or in other prosocial behaviors becomes much more apparent.

The paper contributes to a better conceptual understanding of prosocial motivation. It extends the findings by Kjeldsen and Jacobsen (forthcoming) who provided one of the first studies on PSM using a longitudinal perspective. They found that PSM can vary significantly after employees have finished their training and begun working. Elaborating on this, our paper's panel study suggests that - though change in people's motivation at the beginning of their careers is possible - in the long run, public and private employees’ prosocial attitudes seem to remain quite stable. This also addresses the broader theoretical issue raised by Wright and Grant (2010) who asked whether prosocial motivation is a dynamic state or a static trait and whether the public sector attracts employees with strong social values and/or helps to enforce those through socialization. This paper has only found evidence in support of the “stability” and the "attraction” hypotheses, though we noted existing limitations, such as not being able to follow one cohort from the beginning of their career until the end. A final theoretical insight from this paper is that we learned more about the behavioral effects of prosocial motivation, which can be both complementary and substitutional. One the one hand, prosocial motivation seems to be a generic attitude that guides people's action more broadly and which is capable of triggering several prosocial behaviors simultaneously. Hence, we shall not conceptualize prosocial motivation as a "need" that loses strength once it has found fulfillment through one outlet. On the other hand, limited resources and capacity create tradeoffs for employees, even if prosocially driven, so that increases in prosocial motivation across time might trigger related behaviors, however, at the risk of neglecting others. 
We can also draw some conclusions for the practice of public management. From our finding that differences in prosocial values are significant among employees but only marginally vary across time as a function of socialization; we can infer that recruiting the “right” people is important. Recruiting a critical mass of people with a strong prosocial motivation might help to create a social norm in favor of related values and thus strengthen socialization effects. In order to do so, managers will need to emphasize such values in job listings and assessment centers and link them to their organization's mission in order to be able to attract this type of employee.

Considering our examination of the effects of prosocial motivation, there is good and bad news. The good news is that in general different behaviors do not have to compete for a person's prosocial motivation. Prosocially driven public employees will not turn their back on their organizations and will only focus on volunteering if they feel that their job does not allow them to have social impact. However, we can also conclude that people’s prosocial motivation does not seem to be an unlimited resource. Particularly when managers aim at stimulating employees’ prosocial attitudes, no matter what their baseline motivational level was, in order to increase their work effort, our longitudinal analysis revealed that this requires cutting down on other behaviors, such as volunteering. Thus, managers need to be aware that this way of increasing employees’ persistence comes at a price and should only be made use of in moderation. Looking at this from a work-life-balance perspective, we could speculate that other-oriented employees will be the most satisfied when they can make a difference through their work and through volunteering. But such a hypothesis clearly calls for further research. 


\section{References}

Allison, P. D. 2005. Fixed effects regression methods for longitudinal data using SAS. Cary N.C: SAS Institute.

Andersen, L. B., T. Pallesen and L. H. Pedersen. 2011. "Does Ownership Matter? Public Service Motivation Among Physiotherapists in the Private and Public Sectors in Denmark.” Review of Public Personnel Administration 31(1): 10-27.

Batson, C. D. 1987. “Prosocial motivation: Is it ever truly altruistic?” Pp. 65-122. in L. Berkowitz, ed., Advances in experimental social psychology: Vol. 20. Advances in experimental social psychology. San Diego: Academic Press.

Bekkers, R. 2005. "Participation in Voluntary Associations: Relations with Resources, Personality, and Political Values.” Political Psychology 26(3): 439-54.

Bright, L. 2005. "Public Employees with high Levels of Public Service Motivation.” Review of Public Personnel Administration 25(2): 138-54.

— 2008. "Does Public Service Motivation Really Make a Difference on the Job Satisfaction and Turnover Intentions of Public Employees?” The American Review of Public Administration 38(2): 149-66.

Bussell, H. and D. Forbes. 2002. "Understanding the volunteer market: the what, where, who and why of volunteering.” International Journal of Nonprofit and Voluntary Sector Marketing 7(3): 244-57.

Cameron, A. C. and P. K. Trivedi. 2005. Microeconometrics: Methods and applications. Cambridge, New York: Cambridge University Press.

Christensen, R. K. and B. E. Wright. 2011. "The Effects of Public Service Motivation on Job Choice Decisions: Disentangling the Contributions of Person-Organization Fit and PersonJob Fit.” Journal of Public Administration Research and Theory 21(4): 723-43.

Clerkin, R. M., S. R. Paynter and J. K. Taylor. 2009. "Public Service Motivation in Undergraduate Giving and: Volunteering Decisions.” The American Review of Public Administration 39(6): 675-98.

Coursey, D., J. L. Brudney, L. Littlepage and J. L. Perry. 2011. "Does Public Service Motivation Matter in Volunteering Domain Choices? A Test of Functional Theory." Review of Public Personnel Administration 31(1): 48-66.

De Dreu, C. K. W. 2006. "Rational self-interest and other orientation in organizational behavior: A critical appraisal and extension of Meglino and Korsgaard (2004).” Journal of applied psychology 91(6): 1245-52.

Ertas, N. 2012. "Public Service Motivation Theory and Voluntary Organizations: Do Government Employees Volunteer More?” Nonprofit and Voluntary Sector Quarterly.

Frietsch, R. and H. Wirth. 2001. "Die Übertragung der Magnitude-Prestigeskala von Wegener auf die Klassifikation der Berufe.” ZUMA Nachrichten 25(48): 139-65.

Gabris, G. T. and G. Simo. 1995. "Public sector motivation as an independent variable affecting career decisions.” Public Personnel Management 24(1): 33.

Georgellis, Y., E. Iossa and V. Tabvuma. 2011. "Crowding Out Intrinsic Motivation in the Public Sector.” Journal of Public Administration Research and Theory 21(3): 473-93. 
Giauque, D., S. Anderfuhren-Biget and F. Varone. 2013. "HRM Practices, Intrinsic Motivators, and Organizational Performance in the Public Sector.” Public Personnel Management.

Grant, A. M. 2008. "Does intrinsic motivation fuel the prosocial fire? Motivational synergy in predicting persistence, performance, and productivity.” Journal of applied psychology 93(1): 48-58.

Grant, A. M. and A. Wrzesniewski. 2010. "I won’t let you down... or will I? Core selfevaluations, other-orientation, anticipated guilt and gratitude, and job performance.” Journal of applied psychology 95(1): 108-21.

Hackl, F., M. Halla and G. J. Pruckner. 2007. "Volunteering and Income ? The Fallacy of the Good Samaritan?” Kyklos 60(1): 77-104.

Halaby, C. N. 2004. "Panel Models in Sociological Research: Theory into Practice.” Annual review of sociology 30: 507-44.

Houston, D. J. 2000. “Public-Service Motivation: A Multivariate Test.” Journal of Public Administration Research and Theory 10(4): 713-28.

Jennings, M. K. and G. B. Markus. 1984. "Partisan Orientations over the Long Haul: Results from the Three-Wave Political Socialization Panel Study.” The American Political Science Review 78(4): 1000-18.

Judd, C. M. and M. A. Milburn. 1980. "The Structure of Attitude Systems in the General Public: Comparisons of a Structural Equation Model.” American Sociological Review 45(4): 627-43.

Judge, T. A., C. J. Thoresen, J. E. Bono and G. K. Patton. 2001. "The Job Satisfaction-Job Performance Relationship: A Qualitative and Quantitative Review.” Psychological Bulletin 127(3): 376-407.

Kelman, S. and J. N. Friedman. 2009. "Performance Improvement and Performance Dysfunction: An Empirical Examination of Distortionary Impacts of the Emergency Room Wait-Time Target in the English National Health Service.” Journal of Public Administration Research and Theory 19(4): 917-46.

Kim, S. 2006. "Public service motivation and organizational citizenship behavior in Korea." International Journal of Manpower 27(8): 722-40.

Kim, S., W. Vandenabeele, B. E. Wright, L. B. Andersen, F. P. Cerase, R. K. Christensen, C. Desmarais et al. 2012. "Investigating the Structure and Meaning of Public Service Motivation across Populations: Developing an International Instrument and Addressing Issues of Measurement Invariance.” Journal of Public Administration Research and Theory 23(1): 79-102.

Kjeldsen, A. M. and C. B. Jacobsen. Forthcoming. "Public Service Motivation and Employment Sector: Attraction or Socialization?” Journal of Public Administration Research and Theory.

Kroll, A. and D. Vogel. Forthcoming. “The PSM-Leadership Fit: A Model Of Performance Information Use.” Public Administration.

Lee, Y.-j. 2011. "Behavioral Implications of Public Service Motivation: Volunteering by Public and Nonprofit Employees.” The American Review of Public Administration 42(1): 104-21. 
Leisink, P. and B. Steijn. 2009. "Public service motivation and job performance of public sector employees in the Netherlands.” International Review of Administrative Sciences 75(1): 35-52.

Lewis, G. B. and S. A. Frank. 2002. "Who Wants to Work for the Government?” Public Administration Review 62(4): 395-404.

Mortimer, J. T. and J. Lorence. 1979. "Work Experience and Occupational Value Socialization: A Longitudinal Study.” The American Journal of Sociology 84(6): 1361-85.

Moynihan, D. P. and S. K. Pandey. 2007. "The Role of Organizations in Fostering Public Service Motivation.” Public Administration Review 67(1): 40-53.

- 2008. "The Ties that Bind: Social Networks, Person-Organization Value Fit, and Turnover Intention.” Journal of Public Administration Research and Theory 18(2): 205-27.

Moynihan, D. P., S. K. Pandey and B. E. Wright. 2012. "Prosocial Values and Performance Management Theory: Linking Perceived Social Impact and Performance Information Use.” Governance 25(3): 463-83.

Naff, K. C. and J. Crum. 1999. "Working for America: Does Public Service Motivation Make a Difference?” Review of Public Personnel Administration 19(3): 5-16.

Pandey, S. K., B. E. Wright and D. P. Moynihan. 2008. "Public Service Motivation and Interpersonal Citizenship Behavior in Public Organizations: Testing a Preliminary Model.” International Public Management Journal 11(1): 89-108.

Perry, J. L. 1996. "Measuring Public Service Motivation: An Assessment of Construct Reliability and Validity." Journal of Public Administration Research and Theory 6(1): 522.

Perry, J. L., J. L. Brudney, D. H. Coursey and L. Littlepage. 2008. “What Drives Morally Committed Citizens? A Study of the Antecedents of Public Service Motivation.” Public Administration Review 68(3): 445-58.

Perry, J. L., A. Hondeghem and L. R. Wise. 2010. "Revisiting the Motivational Bases of Public Service: Twenty Years of Research and an Agenda for the Future.” Public Administration Review 70(5): 681-90.

Perry, J. L. and L. R. Wise. 1990. “The Motivational Bases of Public Service.” Public Administration Review 50(3): 367-73.

Rainey, H. G. 1982. "Reward Preferences among Public and Private Managers: In Search of the Service Ethic.” The American Review of Public Administration 16(4): 288-302.

Rice, T. W. and T. A. Hilton. 1996. "Partisanship over Time: A Comparison of United States Panel Data.” Political Research Quarterly 49(1): 191-201.

Sears, D. and C. Funk. 1999. "Evidence of the Long-Term Persistence of Adults' Political Predispositions.” Journal of Politics 61(1): 1-28.

Simon, H. A. 1959. “Theories of Decision-Making in Economics and Behavioral Science.” The American Economic Review 49(3): 253-83.

Socio-Economic Panel (SOEP). 2010. Data for years 1984-2009, version 26. doi:10.5684/soep.v26.

Steijn, B. 2008. “Person-Environment Fit and Public Service Motivation.” International Public Management Journal 11(1): 13-27. 
Tschirhart, M. 1998. "Understanding the Older Stipended Volunteer: Age-Related Differences among AmeriCorps Members.” Public Productivity \& Management Review 22(1): 35-48.

Tschirhart, M., K. K. Reed, S. J. Freeman and A. L. Anker. 2008. "Is the Grass Greener? Sector Shifting and Choice of Sector by MPA and MBA Graduates.” Nonprofit and Voluntary Sector Quarterly 37(4): 668-88.

Vandenabeele, W. 2008. "Government calling: Public service motivation as an element in selecting government as an employer of choice.” Public Administration 86(4): 1089-105.

_ 2009. "The mediating effect of job satisfaction and organizational commitment on self-reported performance.” International Review of Administrative Sciences 75(1): 11-34.

Vogel, D. 2012. How stable are PSM-related values and what is the effect of age and organizational tenure? Using panel data to give a first answer to an important question on PSM research: A Paper prepared for the Annual Conference of the European Group for Public Administration (EGPA), 5-7 September 2012, Bergen, Norway.

Wagner, G. G., J. R. Frick and J. Schupp. 2007. "The German Socio-Economic Panel Study (SOEP) - Scope, Evolution and Enhancements.” Journal of Applied Social Science Studies (Schmollers Jahrbuch) 127: 139-69.

Wegener, B. 1992. “Concepts and measurement of prestige.” Annual review of sociology 18(1): 253-80.

Wittmer, D. 1991. "Serving the People or Serving for Pay: Reward Preferences among Government, Hybrid Sector, and Business Managers.” Public Productivity \& Management Review 14(4): 369-83.

Wooldridge, J. M. 2010. Econometric analysis of cross section and panel data. 2nd ed. Cambridge, Mass: MIT Press.

Wright, B. E. 2007. “Public Service and Motivation: Does Mission Matter?” Public Administration Review 67(1): 54-64.

Wright, B. E. and R. K. Christensen. 2010. "Public Service Motivation: A Test of the Job Attraction-Selection-Attrition Model.” International Public Management Journal 13(2): 155-76.

Wright, B. E. and A. M. Grant. 2010. "Unanswered Questions about Public Service Motivation: Designing Research to Address Key Issues of Emergence and Effects.” Public Administration Review 70(5): 691-700.

Wright, B. E., D. P. Moynihan and S. K. Pandey. 2012. "Pulling the Levers: Transformational Leadership, Public Service Motivation, and Mission Valence.” Public Administration Review 72(2): 206-15.

Wright, B. E. and S. K. Pandey. 2008. "Public Service Motivation and the Assumption of Person-Organization Fit: Testing the Mediating Effect of Value Congruence.”

Administration \& Society 40(5): 502-21. 


\section{Tables and Figures}

Table 1: Descriptive Statistics and Pooled Correlations

\begin{tabular}{|c|c|c|c|c|c|c|c|c|c|c|c|c|c|c|}
\hline & Mean & S.D. & Range & (1) & $(2)$ & (3) & (4) & (5) & (6) & (7) & (8) & (9) & (10) & (11) \\
\hline (3) Social Involvement & 1.92 & 0.68 & $1-4$ & 0.01 & 0.27 & 1.00 & & & & & & & & \\
\hline (5) Political Interest & 2.25 & 0.74 & $1-4$ & 0.05 & 0.17 & 0.43 & 0.06 & 1.00 & & & & & & \\
\hline (6) Job Satisfaction & 7.06 & 1.93 & $0-10$ & 0.00 & 0.05 & 0.01 & 0.04 & 0.03 & 1.00 & & & & & \\
\hline (7) Org. Tenure & 11.20 & 26.79 & metric & -0.03 & 0.08 & 0.03 & -0.03 & 0.09 & -0.01 & 1.00 & & & & \\
\hline (10) Age & 40.12 & 10.54 & metric & -0.03 & 0.05 & 0.07 & -0.08 & 0.19 & -0.03 & 0.45 & 0.17 & 0.13 & 1.00 & \\
\hline (11) Years of Education & 12.10 & 2.56 & metric & 0.11 & 0.10 & 0.22 & 0.03 & 0.29 & 0.03 & -0.03 & 0.67 & 0.30 & 0.15 & 1.00 \\
\hline 12) Gender (Female) & 0.37 & 0.48 & $0-1$ & -0.12 & -0.15 & -0.03 & 0.15 & -0.20 & -0.03 & -0.04 & 0.08 & -0.37 & 0.00 & 0.02 \\
\hline
\end{tabular}


Figure 1: Prosocial Attitudes across Sectors and Time $(n=1,413)$
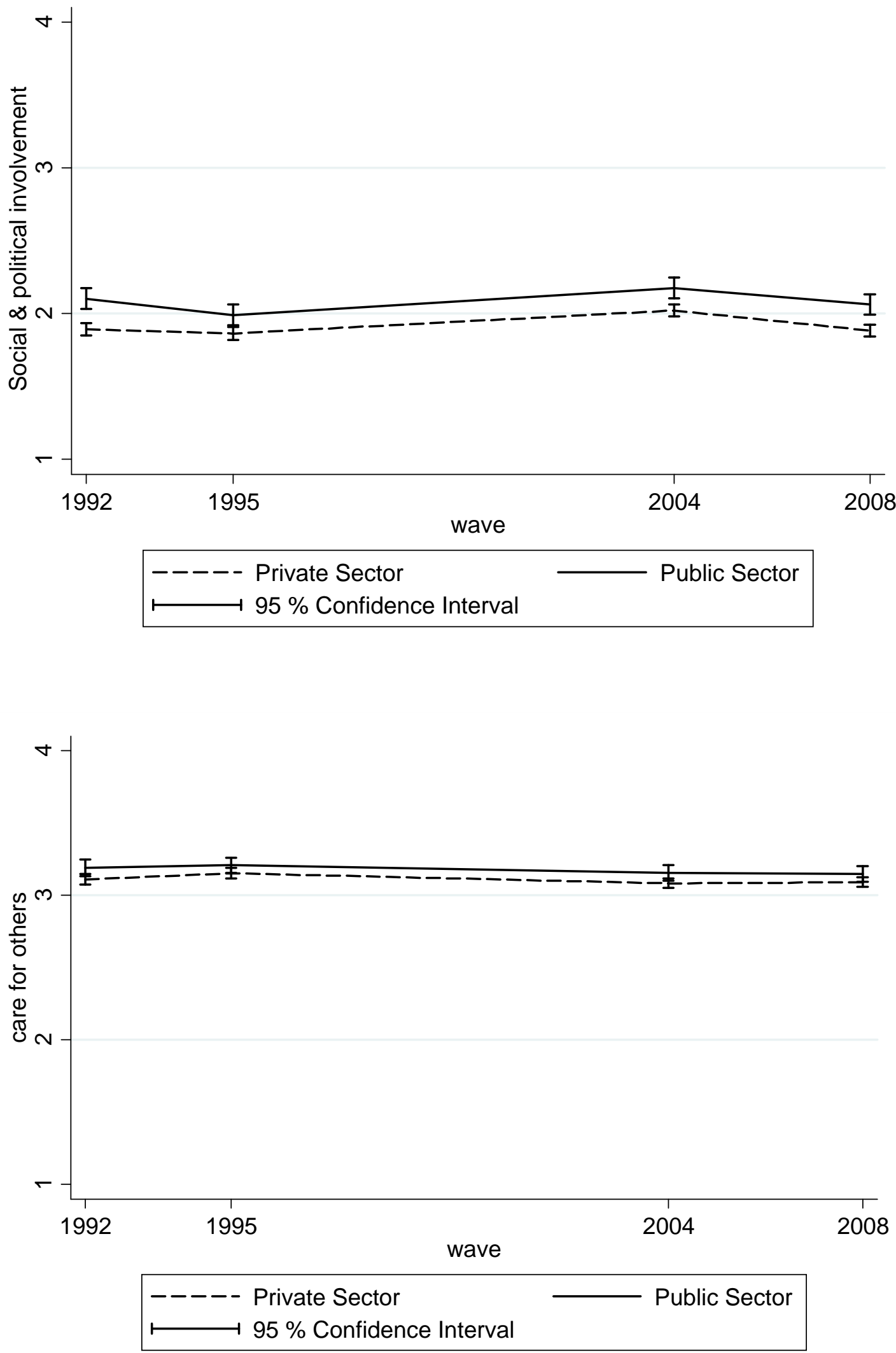
Table 2: Stability of Prosocial Attitudes

\begin{tabular}{lcccc}
\hline & \multicolumn{2}{c}{$\begin{array}{c}\text { Social \& Political } \\
\text { Involvement }\end{array}$} & \multicolumn{2}{c}{ Care for Others } \\
& Private & Public & Private & Public \\
\hline $\begin{array}{l}\text { Part A } \\
\text { Mean \# of Points Moved }\end{array}$ & 1.36 & 1.28 & 1.13 & 0.98 \\
& & & & \\
Part B (in \%) & & & & \\
Stable or Movement =1 & 58.4 & 58.6 & 63.7 & 68.0 \\
Absolute Movement = 2 & 27.1 & 28.0 & 26.1 & 26.2 \\
Absolute Movement = 3+ & 14.6 & 13.4 & 10.2 & 8.9 \\
& & & & \\
Part C (in \%) & & & & \\
Stable 1992 and 1995 & 58.3 & 61.0 & 62.7 & 67.4 \\
Stable 1995 and 2004 & 56.7 & 56.3 & 62.5 & 67.7 \\
Stable 2004 and 2008 & 58.6 & 64.4 & 65.5 & 68.4 \\
Stable 1992 and 2008 & 51.5 & 59.8 & 60.3 & 65.6 \\
\hline
\end{tabular}


Table 3: Cross-Sectional Effects on Behaviors (OLS Regressions with clustered SE)

\begin{tabular}{|c|c|c|c|c|}
\hline \multirow{4}{*}{ Prosocial Attitudes } & \multicolumn{2}{|c|}{ Volunteering } & \multicolumn{2}{|c|}{ Persistence } \\
\hline & \multirow{3}{*}{$\begin{array}{c}(1) \\
\text { Private Sector }\end{array}$} & \multirow{3}{*}{$\begin{array}{c}\text { (2) } \\
\text { Public Sector }\end{array}$} & \multirow{3}{*}{$\begin{array}{c}\text { (3) } \\
\text { Private Sector }\end{array}$} & \multirow{3}{*}{$\begin{array}{c}(4) \\
\text { Public Sector } \\
\end{array}$} \\
\hline & & & & \\
\hline & & & & \\
\hline $\begin{array}{l}\text { Social \& Political } \\
\text { Involvement }\end{array}$ & $\begin{array}{l}0.247^{* * *} \\
(0.000)\end{array}$ & $\begin{array}{l}0.209^{* * *} \\
(0.000)\end{array}$ & $\begin{array}{l}-0.028 \\
(0.187)\end{array}$ & $\begin{array}{l}0.080^{* *} \\
(0.041)\end{array}$ \\
\hline Care for Others & $\begin{array}{l}0.034^{*} \\
(0.050)\end{array}$ & $\begin{array}{l}-0.010 \\
(0.753)\end{array}$ & $\begin{array}{c}0.025 \\
(0.220)\end{array}$ & $\begin{array}{l}0.108^{* * *} \\
(0.000)\end{array}$ \\
\hline \multicolumn{5}{|l|}{ Controls } \\
\hline Political Interest & $\begin{array}{c}0.033 \\
(0.149)\end{array}$ & $\begin{array}{l}-0.005 \\
(0.899)\end{array}$ & $\begin{array}{l}-0.031 \\
(0.189)\end{array}$ & $\begin{array}{c}0.047 \\
(0.240)\end{array}$ \\
\hline Job Satisfaction & $\begin{array}{l}0.051^{* * *} \\
(0.006)\end{array}$ & $\begin{array}{c}0.005 \\
(0.890)\end{array}$ & $\begin{array}{c}-0.042^{* *} \\
(0.041)\end{array}$ & $\begin{array}{l}-0.017 \\
(0.630)\end{array}$ \\
\hline Org. Tenure & $\begin{array}{l}0.060^{* *} \\
(0.017)\end{array}$ & $\begin{array}{c}0.053 \\
(0.308)\end{array}$ & $\begin{array}{l}-0.051^{* *} \\
(0.034)\end{array}$ & $\begin{array}{c}-0.031 \\
(0.605)\end{array}$ \\
\hline Job Prestige & $\begin{array}{c}0.006 \\
(0.820)\end{array}$ & $\begin{array}{l}-0.008 \\
(0.884)\end{array}$ & $\begin{array}{c}0.047 \\
(0.167)\end{array}$ & $\begin{array}{l}-0.146^{* *} \\
(0.019)\end{array}$ \\
\hline Income (log) & $\begin{array}{l}-0.035 \\
(0.175)\end{array}$ & $\begin{array}{c}0.046 \\
(0.250)\end{array}$ & $\begin{array}{c}0.210^{* * *} \\
(0.000)\end{array}$ & $\begin{array}{l}0.097^{* *} \\
(0.022)\end{array}$ \\
\hline Age & $\begin{array}{c}0.010 \\
(0.673)\end{array}$ & $\begin{array}{l}-0.006 \\
(0.908)\end{array}$ & $\begin{array}{c}-0.049^{* *} \\
(0.024)\end{array}$ & $\begin{array}{c}-0.020 \\
(0.722)\end{array}$ \\
\hline Years of Education & $\begin{array}{c}0.025 \\
(0.374)\end{array}$ & $\begin{array}{c}0.049 \\
(0.353)\end{array}$ & $\begin{array}{c}0.060^{*} \\
(0.064)\end{array}$ & $\begin{array}{l}0.137^{* *} \\
(0.037)\end{array}$ \\
\hline Sex (female) & $\begin{array}{c}-0.125^{* * *} \\
(0.000)\end{array}$ & $\begin{array}{c}-0.224^{* * *} \\
(0.000)\end{array}$ & $\begin{array}{l}-0.024 \\
(0.299)\end{array}$ & $\begin{array}{c}-0.145^{* * *} \\
(0.000)\end{array}$ \\
\hline Persistence & $\begin{array}{c}0.014 \\
(0.438)\end{array}$ & $\begin{array}{l}-0.024 \\
(0.493)\end{array}$ & - & - \\
\hline Volunteering & - & - & $\begin{array}{c}0.015 \\
(0.433)\end{array}$ & $\begin{array}{l}-0.025 \\
(0.487)\end{array}$ \\
\hline Observations & 3101 & 1064 & 3101 & 1064 \\
\hline Adjusted $R^{2}$ & 0.096 & 0.112 & 0.062 & 0.062 \\
\hline
\end{tabular}

Standardized beta coefficients; $p$-values in parentheses

${ }^{*} p<.1,{ }^{* *} p<.05,{ }^{* * *} p<.01$ 


\begin{tabular}{|c|c|c|c|c|}
\hline & \multicolumn{2}{|c|}{ Volunteering } & \multicolumn{2}{|c|}{ Persistence } \\
\hline & (1) & (2) & (3) & (4) \\
\hline & Private Sector & Public Sector & Private Sector & Public Sector \\
\hline \multicolumn{5}{|l|}{ Prosocial Attitudes } \\
\hline Social \& Political & $0.123^{* * *}$ & $0.103^{* * *}$ & 0.007 & 0.031 \\
\hline Involvement & $(0.000)$ & $(0.010)$ & $(0.765)$ & $(0.498)$ \\
\hline Care for Others & 0.013 & $-0.075^{* *}$ & 0.023 & $0.082^{* *}$ \\
\hline \multirow{2}{*}{\multicolumn{5}{|c|}{ Controls }} \\
\hline & & & & \\
\hline \multirow[t]{2}{*}{ Political Interest } & $0.051^{*}$ & -0.049 & $-0.065^{* *}$ & -0.091 \\
\hline & $(0.052)$ & $(0.347)$ & $(0.031)$ & $(0.130)$ \\
\hline \multirow[t]{2}{*}{ Job Satisfaction } & 0.001 & 0.004 & -0.024 & 0.033 \\
\hline & $(0.947)$ & $(0.906)$ & $(0.289)$ & $(0.432)$ \\
\hline \multirow[t]{2}{*}{ Org. Tenure } & 0.012 & $-0.244^{* * *}$ & -0.027 & -0.023 \\
\hline & $(0.678)$ & $(0.008)$ & $(0.428)$ & $(0.830)$ \\
\hline \multirow[t]{2}{*}{ Job Prestige } & -0.015 & -0.075 & $0.119^{* * *}$ & -0.062 \\
\hline & $(0.671)$ & $(0.357)$ & $(0.003)$ & $(0.512)$ \\
\hline \multirow[t]{2}{*}{ Income (log) } & $-0.055^{*}$ & 0.025 & $0.191^{* * *}$ & 0.076 \\
\hline & $(0.060)$ & $(0.611)$ & $(0.000)$ & $(0.177)$ \\
\hline \multirow[t]{2}{*}{ Age } & $0.098^{* * *}$ & $0.234^{* * *}$ & -0.043 & 0.033 \\
\hline & $(0.001)$ & $(0.007)$ & $(0.186)$ & $(0.745)$ \\
\hline \multirow[t]{2}{*}{ Persistence } & 0.023 & -0.039 & - & - \\
\hline & $(0.251)$ & $(0.231)$ & & \\
\hline \multirow[t]{2}{*}{ Volunteering } & - & - & 0.030 & -0.052 \\
\hline & & & $(0.251)$ & $(0.231)$ \\
\hline Observations & 3135 & 1079 & 3135 & 1079 \\
\hline n (Individuals) & 1187 & 373 & 1187 & 373 \\
\hline Within-R ${ }^{2}$ & 0.0347 & 0.0335 & 0.0274 & 0.0188 \\
\hline rho & 0.554 & 0.538 & 0.449 & 0.407 \\
\hline
\end{tabular}

Standardized beta coefficients; $p$-values in parentheses

${ }^{*} p<.1,{ }^{* *} p<.05,{ }^{* * *} p<.01$ 


\section{Appendix: Measures}

\begin{tabular}{|c|c|}
\hline Variable & Operationalization \\
\hline $\begin{array}{l}\text { Persistence at } \\
\text { Work }\end{array}$ & $\begin{array}{l}\text { Overtime in hours per week } \\
\text { (metric) }\end{array}$ \\
\hline Volunteering & $\begin{array}{l}\text { Now some questions about your free-time. Please indicate how often } \\
\text { you take part in each activity ... } \\
\ldots \text { Volunteering in clubs, associations or social services ( } 4=\text { at least } \\
\text { once a week; } 3 \text { = at least once a month; } 2=\text { seldom; } 1=\text { never) }\end{array}$ \\
\hline $\begin{array}{l}\text { Importance of } \\
\text { Social \& Political } \\
\text { Involvement }\end{array}$ & $\begin{array}{l}\text { Various things can be important for various people. Are the following } \\
\text { things ... currently ... for you? } \\
\text {..to be politically and/or socially involved } \\
\text { (1= not at all important; } 4 \text { = very important) }\end{array}$ \\
\hline Care for Others & $\begin{array}{l}\text { Various things can be important for various people. Are the following } \\
\text { things ... currently ... for you? } \\
\text {..to be there for others } \\
\text { (1 = not at all important; } 4 \text { = very important) }\end{array}$ \\
\hline Political Interest & $\begin{array}{l}\text { Generally speaking, how much are you interested in politics? } \\
(1=\text { not at all; } 4 \text { = very much) }\end{array}$ \\
\hline Job Satisfaction & $\begin{array}{l}\text { How satisfied are you today with the following areas of your life ... } \\
\ldots \text { with your job? } \\
(0=\text { totally unhappy; } 10=\text { totally happy) }\end{array}$ \\
\hline $\begin{array}{l}\text { Organizational } \\
\text { Tenure }\end{array}$ & $\begin{array}{l}\text { When did you start your current position } \\
\text { [answer was subtracted from wave] }\end{array}$ \\
\hline Job Prestige & $\begin{array}{l}\text { Value on the Magnitude Prestige Scale (Wegener 1992). Value is } \\
\text { assigned based on the German Federal Statistical Office's occupational } \\
\text { classification of } 1992 \text { (KLAS). The procedure has been documented in } \\
\text { Frietsch and Wirth (2001) }\end{array}$ \\
\hline $\log ($ Income $)$ & How high was your income from employment last month (gross)? \\
\hline Age & [wave] - [year of birth] \\
\hline Years of Education & $\begin{array}{l}\text { Variable generated on the basis of respondents' type of education and } \\
\text { training }\end{array}$ \\
\hline Sex & Dummy Variable $(0=$ male; 1 = female $)$ \\
\hline
\end{tabular}

